\title{
Genome-wide association study of Alzheimer's disease brain imaging biomarkers and neuropsychological phenotypes in the EMIF-AD Multimodal Biomarker Discovery dataset
}

1 Jan Homann ${ }^{1 \S}$, Tim Osburg ${ }^{1 \S}$, Olena Ohlei ${ }^{1}$, Valerija Dobricic ${ }^{1}$, Laura Deecke ${ }^{1}$, Isabelle Bos ${ }^{2,3}$, 2 Rik Vandenberghe ${ }^{4,5}$, Silvy Gabel ${ }^{4}$, Philip Scheltens ${ }^{3}$, Charlotte E. Teunissen ${ }^{6}$, Sebastiaan Engelborghs $^{7,8}$, Giovanni Frisoni, ${ }^{9,10}$, Olivier Blin ${ }^{11}$, Jill C. Richardson ${ }^{12}$, Regis Bordet ${ }^{13}$, Alberto Lleó $^{14}$, Daniel Alcolea ${ }^{14}$, Julius Popp ${ }^{15,16}$, Christopher Clark ${ }^{15}$, Gwendoline Peyratout ${ }^{16}$, Pablo Martinez-Lage $^{17}$, Mikel Tainta ${ }^{17}$, Richard J. B. Dobson ${ }^{18}$, Cristina Legido-Quigley ${ }^{19,20}$, Kristel Sleegers $^{21,22}$, Christine Van Broeckhoven ${ }^{21,22}$, Michael Wittig ${ }^{23}$, Andre Franke ${ }^{23}$, Christina $M$. $7 \quad$ Lill $^{1}$, Kaj Blennow ${ }^{24,25}$, Henrik Zetterberg ${ }^{24,25,26,27}$, Simon Lovestone ${ }^{28}$, Johannes Streffer ${ }^{29,30}$, 8 Mara ten Kate ${ }^{3,31}$, Stephanie J. B. Vos ${ }^{2}$, Frederik Barkhof ${ }^{31,32}$, Pieter Jelle Visser ${ }^{2,3,33}$, and Lars 9 Bertram ${ }^{1,34}$

\section{$\S$ These authors contributed equally}

${ }^{1}$ Lübeck Interdisciplinary Platform for Genome Analytics (LIGA), University of Lübeck, Lübeck, Germany

${ }^{2}$ Department of Psychiatry and Neuropsychology, School for Mental Health and Neuroscience, Alzheimer Centrum Limburg, Maastricht University, Maastricht, the Netherlands

${ }^{3}$ Alzheimer Center Amsterdam, Department of Neurology, Amsterdam University Medical Centers, Amsterdam Neuroscience, Vrije Universiteit Amsterdam, Amsterdam, the Netherlands

${ }^{4}$ Laboratory for Cognitive Neurology, Department of Neurosciences, KU Leuven, Leuven, Belgium

${ }^{5}$ Neurology Service, University Hospital Leuven, Leuven, Belgium

${ }^{6}$ Neurochemistry Laboratory, Department of Clinical Chemistry, Amsterdam Neuroscience, Amsterdam University Medical Centers, Vrije Universiteit, Amsterdam, the Netherlands

${ }^{7}$ Department of Biomedical Sciences, University of Antwerp, Antwerp, Belgium

${ }^{8}$ Department of Neurology and Center for Neurosciences, Universitair Ziekenhuis Brussel and Vrije

Universiteit Brussel (VUB), Brussels, Belgium

${ }^{9}$ University of Geneva, Geneva, Switzerland

${ }^{10}$ IRCCS Istituto Centro San Giovanni di Dio Fatebenefratelli, Brescia, Italy

${ }^{11}$ AIX Marseille University, INS, Ap-hm, Marseille, France

${ }^{12}$ Neurosciences Therapeutic Area, GlaxoSmithKline R\&D, Stevenage, UK

${ }^{13}$ University of Lille, Inserm, CHU Lille, Lille, France

${ }^{14}$ Memory Unit, Neurology Department. Hospital de Sant Pau, Barcelona and Centro de

Investigación Biomédica en Red en enfermedades Neurodegenerativas (CIBERNED), Madrid, Spain ${ }^{16}$ Old Age Psychiatry, Department of Psychiatry, University Hospital of Lausanne, Lausanne, 
medRxiv preprint doi: https://doi.org/10.1101/2021.12.22.21268168; this version posted December 27, 2021. The copyright holder for this preprint (which was not certified by peer review) is the author/funder, who has granted medRxiv a license to display the preprint in perpetuity.

$34{ }^{17}$ Department of Neurology, Center for Research and Advanced Therapies, CITA-Alzheimer

35 Foundation, San Sebastian, Spain

$36{ }^{18}$ Department of Biostatistics and Health Informatics, Institute of Psychiatry, Psychology and

37 Neuroscience, King's College London, London, UK

$38 \quad{ }^{19}$ Steno Diabetes Center, Copenhagen, Denmark

3920 Institute of Pharmaceutical Sciences, King's College London, London, UK

$40 \quad{ }^{21}$ Complex Genetics of Alzheimer's Disease Group, Center for Molecular Neurology, VIB, Antwerp, 41 Belgium

$42 \quad{ }^{22}$ Department of Biomedical Sciences, University of Antwerp, Antwerp, Belgium

4323 Institute of Clinical Molecular Biology, Christian-Albrechts-University of Kiel, Kiel, Germany

$44 \quad{ }^{24}$ Institute of Neuroscience and Physiology, Department of Psychiatry and Neurochemistry, The

45 Sahlgrenska Academy, University of Gothenburg, Gothenburg, Sweden

$46 \quad{ }^{25}$ Clinical Neurochemistry Laboratory, Sahlgrenska University Hospital, Mölndal, Swe den

$47 \quad{ }^{26}$ Department of Neurodegenerative Disease, UCL Queen Square Institute of Neurology, Queen

48 Square, London, UK

$49 \quad{ }^{27}$ UK Dementia Research Institute at UCL, London, UK

${ }^{28}$ Department of Psychiatry, University of Oxford, Oxford, UK (currently employed at Janssen-Cilag)

${ }^{29}$ Reference Center for Biological Markers of Dementia (BIODEM), Institute Born-Bunge,

52 University of Antwerp, Antwerp, Belgium

$53 \quad{ }^{30}$ AC Immune SA, EPFL Innovation Park, Lausanne, Switzerland

$54{ }^{31}$ Department of Radiology and Nuclear Medicine, Amsterdam University Medical Centers,

55 Amsterdam Neuroscience, Amsterdam, the Netherlands

${ }^{32}$ Institutes of Neurology and Healthcare Engineering, University College London, London, UK

${ }^{33}$ Department of Neurobiology, Care Sciences and Society, Division of Neurogeriatrics, Karolinska

58 Institutet, Stockholm, Sweden

$59 \quad{ }^{34}$ Department of Psychology, University of Oslo, Oslo, Norway

$60 *$ Correspondence:

61 Prof. Lars Bertram, Lübeck Interdisciplinary Platform for Genome Analytics (LIGA), University of

62 Lübeck, Ratzeburger Allee 160, V50-319, 23562 Lübeck, Germany, phone: +49 4513101 7491, e-

63 mail: lars.bertram@uni-luebeck.de

64 Keywords: genome-wide association study, GWAS, X chromosome, Alzheimer's disease, AD, 65 MRI, imaging, cognitive function 
medRxiv preprint doi: https://doi.org/10.1101/2021.12.22.21268168; this version posted December 27, 2021. The copyright holder for this preprint (which was not certified by peer review) is the author/funder, who has granted medRxiv a license to display the preprint in perpetuity.

All rights reserved. No reuse allowed without permission in EMIF-AD MBD dataset

\section{Abstract}

Alzheimer's disease (AD) is the most frequent neurodegenerative disease with an increasing prevalence in industrialized, ageing populations. AD susceptibility has an established genetic basis which has been the focus of a large number of genome-wide association studies (GWAS) published over the last decade. Most of these GWAS used dichotomized clinical diagnostic status, i.e. case vs. control classification, as outcome phenotypes, without the use of biomarkers. An alternative and potentially more powerful study design is afforded by using quantitative AD-related phenotypes as GWAS outcome traits, an analysis paradigm that we followed in this work. Specifically, we utilized genotype and phenotype data from $n=931$ individuals collected under the auspices of the European Medical Information Framework for Alzheimer's Disease Multimodal Biomarker Discovery (EMIFAD MBD) study to perform a total of 19 separate GWAS analyses. As outcomes we used five magnetic resonance imaging (MRI) traits and seven cognitive performance traits. For the latter, longitudinal data from at least two timepoints were available in addition to cross-sectional assessments at baseline. Our GWAS analyses revealed several genome-wide significant associations for the neuropsychological performance measures, in particular those assayed longitudinally. Among the most noteworthy signals were associations in or near EHBP1 (EH domain binding protein 1; on chromosome $2 \mathrm{p} 15$ ) and $C E P 112$ (centrosomal protein 112;17q24.1) with delayed recall in a memory performance test. On the X chromosome, which is often excluded in other GWAS, we identified a genome-wide significant signal near ILIRAPLI (interleukin 1 receptor accessory protein like 1; Xp21.3). While polygenic score (PGS) analyses showed the expected strong associations with SNPs highlighted in relevant previous GWAS on hippocampal volume and cognitive function, they did not show noteworthy associations with recent AD risk GWAS findings. In summary, our study highlights the power of using quantitative endophenotypes as outcome traits in AD-related GWAS analy ses and nominates several new loci not previously implicated in cognitive decline.

\section{Introduction}

Alzheimer's disease is the most common neurodegenerative disease in humans and the most common form of dementia. In 2018, estimates were published that 50 million dementia patients exist worldwide, about two-third of whom were diagnosed with AD (Patterson, 2018). Pathologically, AD is characterized by the accumulation of extracellular amyloid $\beta(\mathrm{A} \beta)$ peptide deposits ("plaques") and intracellular hyperphosphorylated tau protein aggregates ("tangles") in the brain, leading to synaptic dysfunction, neuroinflammation, neuronal loss, and, ultimately, onset of cognitive decline (Sperling et al, 2014; Mattsson et al., 2015). Genetically, AD is a heterogeneous disorder with both monogenic and polygenic forms. The former is caused by highly penetrant but rare mutations in three genes encoding the amyloid beta precursor protein (APP) and presenilins 1 and 2 (PSEN1/PSEN2), which only make up a small fraction ( $<<5 \%)$ of all AD cases (Cacace et al., 2016). Most patients, however, suffer from "polygenic AD", which is determined by the action (and interaction) of numerous independent genomic variants, likely in concert with nongenetic factors, such as environmental exposures (e.g., head trauma) and lifestyle choices (e.g., alcohol consumption and cigarette smoking) (Bertram and Tanzi, 2020). Based on results from the currently most recent and largest genome-wide association study (GWAS) performed in AD, there are now 38 independent loci showing genomewide significant association with disease risk (Wightman et al., 2021). The most strongly and most consistently associated $\mathrm{AD}$ risk gene is $A P O E$, which encodes apolipoprotein $\mathrm{E}$, a cholesterol transport protein that has been implicated in numerous amyloid-specific pathways, including amyloid trafficking, as well as plaque clearance (Holtzman et al., 2012). Although the heritability of 
medRxiv preprint doi: https://doi.org/10.1101/2021.12.22.21268168; this version posted December 27, 2021. The copyright holder for this preprint (which was not certified by peer review) is the author/funder, who has granted medRxiv a license to display the preprint in perpetuity.

111 polygenic AD is estimated to be around 60-80\% (Gatz et al., 2016), APOE and the other currently

112 known 37 independent risk loci explain only part of the diseas e's phenotypic variance (Wightman et al., 2021). While most AD GWAS only consider clinically diagnosed "probable AD" cases and cognitively unimpaired controls, involving a risk for mis-diagnosis of patients and inclusion of preclinical AD cases as controls, additional information about the genetic architecture of AD and additional statistical power is also afforded by using "endophenotypes" related to AD, ideally measured on a quantitative scale such as biomarker data, imaging, or neurocognitive performance (Gottesman and Gould, 2003; MacRae and Vasan, 2011; Zhang et al., 2020).

119 In our study, we expand earlier work from our group (Hong et al., 2020; Hong et al., 2021) derived Discovery (EMIF-AD MBD) sample (Bos et al., 2018). Specifically, in two previous GWAS we set out to identify variants underlying variation in several cerebrospinal fluid (CSF) phenotypes, such as levels of CSF A $\beta$ and tau protein (Hong et al., 2020), or neurofilament light (NfL) chain, chitinase-3like protein 1 (YKL-40), and neurogranin $(\mathrm{Ng})$, which reflect axonal damage, astroglial activation, and synaptic degeneration, respectively (Hong et al., 2021). However, the EMIF-AD MBD dataset features several other quantitative phenotypes, including cross-sectional MRI measurements and cross sectional and longitudinal neuropsychological tests, which are used as outcome traits in the current study. Specifically, we performed GWAS and polygenic score (PGS) analyses on seven neuropsychological (using both cross-sectional and longitudinal data) and five brain imaging phenotypes (using cross-sectional data from MRI scans). In the 19 performed GWAS scans (which also included the $\mathrm{X}$ chromosome), we identified a total of 13 genome-wide significant loci highlighting several novel genes showing association with the analyzed traits. While we do not see a noteworthy overlap in the genetic architectures underlying our "endophenotypes" and AD by polygenic score (PGS) analysis, we did observe significant correlations in PGS constructed from earlier GWAS on hippocampal volume (Hibar et al., 2017) and general cognitive function (Davies et al., 2018) with the respective phenotypes in EMIF-AD MBD. Taken together, our novel results pinpoint several new genetic loci potentially involved in AD-related pathophysiology.

\section{Materials and Methods}

\section{$140 \quad$ 2.1 Sample description}

141 Analyses were based on the EMIF-AD MBD dataset which was collected across eleven different

142 European study centers (Bos et al., 2018). In total, this dataset included 1221 (563 [46\%] female; mean age $=67.9$ years, $\mathrm{SD}=8.3$ ) individuals from three diagnostic stages: normal controls $(\mathrm{NC})$, subjects with mild cognitive impairment (MCI) and subjects with a clinical diagnosis of AD. An overview of the quantitative phenotypes investigated in this study is provided in Table 1. Due to partially missing phenotype data (in the neurocognitive domain), the effective sample sizes vary for the different GWAS analyses (see Table 1). The local medical ethical review boards in each participating recruitment center had approved the study prior to commencement. Furthermore, all subjects had provided written informed consent at the time of inclusion in the cohort for use of data, samples and scans (Bos et al., 2018).

\subsection{MRI phenotypes description}

152 The five MRI phenotypes were collected for 862 subjects. Brain MRIs were used to assess

153 hippocampal volume $\left(\mathrm{mm}^{3}\right.$, left and right hemisphere, and sum of both; all adjusted for intracranial 
medRxiv preprint doi: https://doi.org/10.1101/2021.12.22.21268168; this version posted December 27, 2021. The copyright holder for this preprint (which was not certified by peer review) is the author/funder, who has granted medRxiv a license to display the preprint in perpetuity.

154

155

156

157

158

159

160

161

162

163

164

165

166

167

168

169

170

171

172

173

174

175

176

177

178

179

180

181

182

183

184

185

186

187

188

189

190

191

192

193

194

volume), whole brain cortical thickness (in $\mathrm{mm}$ ), and white matter lesions (WML; using the Fazekas scale) (Ten Kate et al., 2018). The Fazekas scale categorizes WMLs into 4 categories: Level 0 (no or almost no lesion), level 1 (multiple punctate lesions), level 2 (early confluent WML), and level 3 (presence of large confluent WML). Details on the scanning procedures and data harmonization across centers can be found in Bos et al. (2018) and Ten Kate et al. (2018).

\subsection{Neuropsychological phenotypes description}

Cross-sectional (and follow-up) data were available for the following seven neuropsychological domains within the EMIF-AD MBD dataset: global cognition (Mini Mental State Examination, MMSE), attention, executive function, language, memory (immediate and delayed) and visuoconstruction. For each cognitive domain, a primary test was selected by Bos et al. (2018). If the preferred test were not available, an alternative priority test from the same cognitive domain was chosen. More details on the neuropsychological tests used for generating these phenotypes can be found in Bos et al. (2018). Raw data on these tests were normalized with the help of a $z$ transformation, so that the data were comparable within a cognitive domain despite representing partially different tests across centers. For the cross-sectional GWAS analyses, the $z$-scores derived from baseline data were used. The number of subjects used for each test can be found in the Supplementary Material. For all seven neuropsychological domains, follow-up data from at least one additional time point were available for each individual and used to construct a longitudinal phenotype using the following formula (which estimates the relative change in cognitive performance per time interval [here: years]):

$$
\frac{\text { Score }_{\text {last }}-\text { Score }_{\text {first }}}{\frac{\text { Score }_{\text {last }}+\text { Score }_{\text {first }}}{2} * \text { interval }}
$$

When calculating longitudinal phenotypes, this formula was applied separately for each neuropsychological test. Outlying scores were determined using false discovery rate (FDR) $<0.05$ estimations and were excluded from all subsequent analyses. Only the most frequently used tests per cognitive domain were included in the final phenotypes. For more information, see Supplementary Material. Both baseline and longitudinal phenotypes were adjusted for age at baseline.

\subsection{DNA extraction, genotype imputation and quality control}

A detailed description of the genotyping procedures, quality control (QC) and subsequent data processing can be found in Hong et al. (2020) and in the Supplementary Material. Here, the same genotype data were used for the GWAS analyses. Briefly, 936 DNA samples were subjected to genome-wide SNP genotyping using the Infinium Global Screening Array (GSA) with Shared Custom Content (Illumina Inc.). Imputation was then performed using Minimac3 (Das et al., 2016). Extensive post-imputation QC resulted in 7,464,105 autosomal SNPs with a minor allele frequency (MAF) $\geq 0.01$ in 888 individuals of European ancestry. More details can be found in the Supplementary Material.

For the $\mathrm{X}$ chromosome, QC was performed separately for male and female subjects for nonpseudoautosomal regions, using slightly different criteria compared to the autosomes (see Supplementary Material). In contrast, pseudoautosomal regions (PAR1 and PAR2) were treated analogously to the autosomal SNPs. After QC, imputations were performed on the Sanger Institute imputation server (https://imputation.sanger.ac.uk/) using the extended HRC reference panel (McCarthy et al., 2016). After imputation, we used the same QC criteria as for the autosomal SNPs 
medRxiv preprint doi: https://doi.org/10.1101/2021.12.22.21268168; this version posted December 27, 2021. The copyright holder for this preprint (which was not certified by peer review) is the author/funder, who has granted medRxiv a license to display the preprint in perpetuity.

195

196

197

198

199

200

201

202

203

204

205

206

207

208

209

210

211

212

213

214

215

216

217

218

219

220

221

222

223

224

225

226

227

228

229

230

231

232

233

234

235

236

237

but performed these separately for female and male data sets, except the HWE test $(P<1.0 \mathrm{E}-4)$ which was performed on all samples combined as recommended previously (Graffelmann and Weir, 2016) and implemented in PLINK2. For males, markers were coded as 0 vs. 2 (instead of 0 vs. 1), to adjust for the missing second X chromosome (as recommended in Smith et al. [2021]).

\subsection{GWAS and post-GWAS analyses}

SNP-based association analyses were performed assuming an additive linear model (command: -glm) using allele dosages (to account for imputation uncertainty) in PLINK2 (Purcell et al., 2007). The covariates included in the analyses were sex, diagnostic status and the first three principal components from a principal component analysis (PCA) to adjust for population-specific differences. Generally, we excluded SNPs from the GWAS analyses with MAF $<0.01$. However, due to differences in the effective sample sizes across phenotypes this threshold was adapted upward (up to 0.04 ) to prevent inflation of test statistics owing to low frequency SNPs (see Table 1 for more details). Diagnostic status was coded with two dummy variables as follows: $\mathrm{NC}=(0,0), \mathrm{MCI}=(0,1)$, $\mathrm{AD}=(1,1)$. For four longitudinal cognitive phenotypes an additional dummy variable was introduced to code for the neuropsychological test used, in cases where two different tests were used for generating these phenotypes. Details can be found in the Supplementary Material.

To explore associations on the $\mathrm{X}$ chromosome that were potentially driven by genetic sex, we additionally conducted the analyses separately in females and males. We then combined these two additional sets of results in a meta-analysis using Stouffer's method as implemented in METAL (Willer et al., 2010). As we found no noteworthy differences in the results using Stouffer's method, only the results from the linear regression analysis in the combined sample are shown.

The FUMA platform (http://fuma.ctglab.n1/; Watanabe et al., 2017) was used for post-GWAS analyses, including gene-based association analyses (via MAGMA (de Leeuw et al., 2015)) and to annotate and visualize the GWAS results. To this end, we defined genome-wide significance at $\alpha<5.0 \mathrm{E}-08$ for the SNP-based analyses while genome-wide suggestive evidence was set at $\alpha<1.0 \mathrm{E}$ 05 . For the gene-based analyses, we adjusted for the number of protein-coding genes examined $(19,485)$ using the Bonferroni method, resulting in a threshold of $\alpha<2.566 \mathrm{E}-06$.

In FUMA, both the SNP annotation and the Combined Annotation Dependent Depletion (CADD) score (Rentzsch et al., 2021) are provided. The main GWAS results are reported only for "independent significant" SNPs, as defined by FUMA. These represent SNPs that are not highly correlated with one another using a threshold of $r^{2}<0.6$ (using reference data from the 1000 Genomes Project).

Subsequently, the top SNPs, i.e., those with the smallest $P$ values per respective phenotype, were examined in more detail using additional tools. First, the Variant Effect Predictor on Ensembl (VEP, http://grch37.ensembl.org/Tools/VEP; McLaren et al., 2016) was used to determine a possibly functional effect due to changes in the coding sequence, e.g. missense variants. Second, SNPs were examined using data from the RegulomeDB database (https://regulomedb.org/regulome-search; Boyle et al., 2012) to assess possible effects on gene expression. Third, we used data from the Genotype-Tissue Expression (GTEx, V8) project portal (https://www.gtexportal.org/home/; Lonsdale et al., 2013) to assess whether SNPs represent expression / splicing quantitative trait loci (eQTLs/sQTLs). While GTEx provides data on gene expression in 54 tissues, we laid particular emphasis in genes expressed in brain. Lastly, we interrogated the GWAS catalogue (https://www.ebi.ac.uk/gwas/home; Buniello et al., 2019) to assess whether any of the top SNPs were 
medRxiv preprint doi: https://doi.org/10.1101/2021.12.22.21268168; this version posted December 27, 2021. The copyright holder for this preprint (which was not certified by peer review) is the author/funder, who has granted medRxiv a license to display the preprint in perpetuity.

previously reported to show association with other phenotypes by GWAS. To this end, we considered genes and loci within a $1 \mathrm{Mb}$ region ( $\pm 500,000 \mathrm{bp})$ around the SNP of interest. In case SNPs not identical to our "top SNP" were reported to show association with an AD-relevant phenotype (brain imaging, cognition, etc.), the LDlink platform (Machiela and Chanock, 2015) was used to determine pairwise LD to top SNPs (https://ldlink.nci.nih.gov/?tab=ldpair). In this context we defined relevant LD using a threshold of $r^{2}>0.6$.

\subsection{Polygenic score (PGS) analysis}

In addition to the primary GWAS analyses described above, we also calculated polygenic scores (PGS) to estimate the extent of genetic correlation with the GWAS results for three other phenotypes. To this end, we used the summary statistics of a GWAS on AD risk (Jansen et al., 2019) as comparison to both phenotypic domains (MRI and neurocognitive performance) of our study, and the GWAS on general cognitive function (Davies et al., 2018) as comparison to the GWAS on neuropsychological phenotypes. Finally, the GWAS on hippocampal volume (Hibar et al., 2018) served as comparison to our GWAS analyses on MRI phenotypes. PGS calculations were performed using PRSice-2 software (Choi and O'Riley, 2019). Statistical analyses fitted general linear regression models with PGS as predictor adjusting for the same covariates as in the primary GWAS analyses: sex, diagnostic status, and PC1-3 (and type of cognitive test, where applicable). To adjust for multiple testing of this arm of our study, we used a conservative threshold based on Bonferroni adjustment $(\alpha<5.0 \mathrm{E}-03=0.05 / 5 * 2$ for the MRI phenotypes, and $\alpha<1.8 \mathrm{E}-03=0.05 / 14 * 2$ for the neuropsychological phenotypes). However, given the (at least partial) correlation between phenotypes, we note that the true threshold is likely somewhere between 0.05 and these Bonferroniadjusted values.

\section{Results}

\subsection{GWAS on MRI phenotypes}

The genomic inflation factor $\lambda$ ranged between 1.004 and 1.012 in all five SNP-based analyses, indicating that the results of the MRI GWAS analyses were not affected by substantial inflation of the test statistics. In the actual association analyses of the five quantitative MRI phenotypes, we identified no genome-wide significant $(P<5.0 \mathrm{E}-08)$ signals but observed 385 variants with at least suggestively significant $(P<1.0 \mathrm{E}-05)$ evidence of association (Supplementary Tables 15-19). The lowest $P$ value was observed with SNP rs16829761 for the Fazekas phenotype $(P=5.08 \mathrm{E}-08$; Supplementary Figure 31), which only fell slightly above the genome-wide significance threshold. According to VEP (McLaren et al., 2016), this variant is located in an intron of the genes IQCJ (protein: IQ motif containing J) and SCHIPI (protein: schwannomin-interacting protein 1). In the GTEx database (Lonsdale et al., 2013), the lead-SNP identified here (rs16829761) is not listed as eQTL or sQTL, which may be due to the comparatively low MAF (0.01). The CADD score, i.e., the in silico predicted deleteriousness, of rs 16829761 is also low at approximately 0.074 . In addition, none of the gene-based GWAS analyses using MAGMA revealed any genome-wide significant signals $(P<2.566 \mathrm{E}-06)$ using the MRI traits analyzed. The genomic inflation factor $\lambda$ ranged between 0.984 and 1.060 in these five gene-based analyses.

\subsection{GWAS on neuropsychological phenotypes}


medRxiv preprint doi: https://doi.org/10.1101/2021.12.22.21268168; this version posted December 27, 2021. The copyright holder for this preprint (which was not certified by peer review) is the author/funder, who has granted medRxiv a license to display the preprint in perpetuity.

279

280

281

282

283

284

285

286

287

288

289

290

291

292

293

294

295

296

297

298

299

300

301

302

303

304

305

306

307

308

309

310

311

312

313

314

315

316

317

318

319

320

321

322

323

324

Across the 14 GWAS performed on cross-sectional and longitudinal neuropsychological phenotypes available in EMIF-AD MBD, there were a total of 13 genome-wide significant loci, two of which were identified via the gene-based analyses using MAGMA (de Leeuw et al., 2015). Three of the genome-wide significant signals were observed in the analyses of cross-sectional phenotype data and ten with longitudinal outcomes. Overall, none of the sets of GWAS results in this arm of our study appeared to be strongly affected by inflation of the genome-wide test statistics as evidenced by genomic inflation factors near 1 (range: 0.969-1.012 in the SNP-based analyses and 0.922-1.036 in the gene-based analyses). Table 2 provides a detailed summary of these genome-wide significant loci, and Figure 1 shows multi-trait Manhattan $(\mathrm{MH})$ plots of the SNP-based GWAS results for crosssectional (Figure 1A) and longitudinal (Figure 1B) analyses (for corresponding QQ plots: see Supplementary Figures 1 and 2). The following two paragraphs highlight the most interesting results in either the analyses of cross-sectional or longitudinal neuropsychological traits.

Analyses of cross-sectional data. The most interesting finding in this domain was elicited by markers in EHBP1 which showed genome-wide significant evidence of association with the delayed recall memory phenotype in the gene-based analysis ( $P=1.17 \mathrm{E}-07$; Table 2; Supplementary Figure 20). The lead SNP (rs6705798) in this region only missed the genome-wide significance threshold by a small margin $(P=8.78 \mathrm{E}-08$; Table 2; Figure 1A). EHBP1 is located on chromosome $2 \mathrm{p} 15$ and encodes EH domain binding protein 1 .

Analyses of longitudinal data. The strongest signal in the longitudinal analyses was elicited by a locus on chromosome 6q27 (rs73045836; $P=7.50 \mathrm{E}-11$; Table 2; Figure 1B; Supplementary Figure 25 ) in the analysis using an immediate memory recall paradigm. This SNP is located in an intron of SMOC2 coding for secreted modular calcium-binding protein 2, which, among other functions, promotes extracellular matrix assembly (Gao et al., 2019). It needs to be noted that with an MAF $\sim 2 \%$ this SNP is rather infrequent which may increase the possibility of representing a false-positive finding. Perhaps more interesting is the association signal observed near SNP rs5943462 (MAF $\sim 0.05$ ) and the visuoconstruction phenotype on the $\mathrm{X}$ chromosome ( $P=1.06 \mathrm{E}-09$; Table 2; Figure 1B; Supplementary Figure 29). This SNP is an intronic variant located in ILIRAPLI encoding interleukin 1 receptor accessory protein-like 1 , which belongs to a class of molecules that regulate synapse formation (Montani et al., 2019). The third highlighted signal in this domain relates to the genomewide significant variant rs74381761 (MAF 0.05) on chromosome 8p23.1 ( $P=1.89 \mathrm{E}-08$; Table 2; Figure 1B; Supplementary Figure 5) which shows association with the longitudinal MMSE phenotype. The lead SNP is located in an intergenic region near TNKS (gene-based $P=4.87 \mathrm{E}-04$; Table 2). This gene encodes the protein tankyrase, which belongs to a class of poly (ADP-ribose) polymerases and is involved in various processes in the body, such as telomere length regulation, the $\mathrm{Wnt} / \beta$-catenin signaling pathway, or glucose transport (Damale et al., 2020). The last featured signal relates to the association observed near SNP rs9652864 (MAF 0.22) on chromosome 17q24.1 $(P=3.20 \mathrm{E}-08$; Table 2; Figure 1B; Supplementary Figure 21) and the delayed recall test. This variant is located in an intron of CEP112, which encodes centrosomal protein 112. Overall, there were eight correlated SNPs in this locus all showing strongly association (Supplementary Table 10).

Comparison of cross-sectional vs. longitudinal GWAS results. After completion of the separate GWAS on cross-sectional and longitudinal outcomes, we assessed whether the results of these two analysis arms showed any overlap. To this end, we followed two approaches: First, we performed a look-up of top results from one paradigm in the equivalent other. Specifically, we checked whether a genome-wide significant SNP from the cross-sectional analyses also had a low $P$ value in the corresponding longitudinal GWAS and vice versa. The lowest corresponding $P$ value was 0.015 (at baseline) for rs 73045828, which attained $P=5.65 \mathrm{E}-09$ in the longitudinal GWAS for immediate 
medRxiv preprint doi: https://doi.org/10.1101/2021.12.22.21268168; this version posted December 27, 2021. The copyright holder for this preprint (which was not certified by peer review) is the author/funder, who has granted medRxiv a license to display the preprint in perpetuity.

325

326

327

328

329

330

331

332

333

334

335

336

337

338

339

340

341

342

343

344

345

346

347

348

349

350

351

352

353

354

355

356

357

358

359

360

361

362

363

364

365

366

367

368 memory (Supplementary Table 21). No further signal overlaps were observed across corresponding cross-sectional and longitudinal phenotypes. Second, we took a more comprehensive approach by comparing a larger set of SNPs across both phenotypic domains. To this end, we constructed PGS from the summary statistics of the cross-sectional GWAS (as an approximate measure of "aggregated SNP effects") and used these PGS as independent variables in a linear model predicting longitudinal outcomes. Effectively, this allowed us to determine how much phenotypic variance in the longitudinal data can be explained by top SNPs of the matching cross-sectional GWAS. Overall, these analyses did not reveal a substantial correlation in genetic results for corresponding phenotypes (Supplementary Table 22), in agreement with the look up of individual SNPs (see above). The best model fit was observed with the PGS for executive function and visuoconstruction, where the GWAS top SNPs from the cross-sectional data used in the PGS explained 4-9\% of the phenotypic variance of the corresponding longitudinal outcomes, respectively (Supplementary Table 22). We note, however, that the PGS method was not designed for computing genetic correlations of non-independent samples (as is the case here), so this analysis must be considered "exploratory", and the reported results represent no more than "upper bounds" of the potential genetic correlations.

\subsection{Role APOE in GWAS on MRI and neuropsychological performance}

Given the substantial role that variants in $A P O E$ play in the genetic architecture of $A D$, we present findings for this locus separately, i.e. the results for SNP rs429358 (which defines the $\varepsilon 4$ allele) and rs 7412 (which defines the $\varepsilon 2$ allele). In relation to the common genotype $\varepsilon 3 / \varepsilon 3$, the risk to develop $\mathrm{AD}$ is increased by a factor of $\sim 3.2$ for genotype $\varepsilon 3 / \varepsilon 4$, while two $\varepsilon 4$ alleles (genotype $\varepsilon 4 / \varepsilon 4$ ) show ORs around 10-12 when compared to normal controls (Neu et al., 2017). The minor allele at rs429358 (84) is overrepresented in the EMIF-AD MBD dataset with an MAF 29\% (the MAF in the general Northern European population is $\sim 16 \%$ ), which is due to the special design of participant recruitment (see Bos et al. (2018)). For the neuropsychological phenotypes, the $P$ values of rs 429358 are unremarkable except for the domain "delayed memory", where $P$ values of 0.0005 and 0.0042 were observed for the baseline and longitudinal analyses, respectively (Supplementary Table 20). In the MRI analyses, the only association signal observed with rs429358 was with hippocampal volume (Supplementary Table 20). Interestingly, this was driven by an association with the volume of the left $(P=0.0002)$ hippocampus, while no association was observed with the corresponding data of the right hemisphere $(P=0.2956)$. We note that for both traits, i.e. delayed memory and left hippocampal volume, the effect direction the corresponding $\beta$ coefficient is consistent with the deleterious effect of the minor (T/\&4) allele at rs 429358 known from the literature (Neu et al., 2017). For the minor allele at rs7412 ( $(22)$ we observed no noteworthy association signals in any of the analyses performed in this study (Supplementary Table 20), although power for this variant was much reduced owing to its lower MAF (4.6\% here, $7.5 \%$ in the general western European control population).

\subsection{Polygenic score (PGS) analyses using published GWAS results}

In these analyses we aimed to estimate the degree of genetic overlap between the MRI and neuropsychological outcomes available in EMIF-AD MBD and other relevant traits from the literature, such as AD risk, using published GWAS summary statistics.

PGS analyses with MRI phenotypes. As expected, the strongest overlap was observed with a prior GWAS also using MRI outcomes. Specifically, we used GWAS results by the ENIGMA group (Hibar et al., 2017) who studied 26 imaging traits in $n=33,536$ individuals. Here, the best overlap was seen with each of the three hippocampal MRI traits (up to $2.7 \%$ variance explained, $P=6.0 \mathrm{E}-06$; Table 3; Supplementary Table 24). In contrast, in PGS analyses using SNPs associated with AD risk 
medRxiv preprint doi: https://doi.org/10.1101/2021.12.22.21268168; this version posted December 27, 2021. The copyright holder for this preprint (which was not certified by peer review) is the author/funder, who has granted medRxiv a license to display the preprint in perpetuity.

(Jansen et al., 2019), we found only one moderate correlation with white matter damage (measured by the Fazekas score). For this trait the AD SNPs explained 1.4\% variance $(P=3.7 \mathrm{E}-03$; Table 3; Supplementary Table 24).

PGS analyses with neuropsychological phenotypes. As for the MRI data, the best fit in the PGS analyses with the neuropsychological phenotypes was observed with a GWAS that also used neurocognitive performance as outcome (Davies et al., 2018). Specifically, this study defined a PCA derived factor for "general cognitive function" which was analyzed in >300,000 individuals. In EMIF-AD MBD, associations with four of the 14 calculated PGS fell below the multiple testing threshold of 1.8E-03 (Table 3). The strongest association was observed with the longitudinal attention function for which the GWAS results from Davies et al. (2018) explained 2.3\% of the phenotypic variance $(P=1.79 E-03$, Table 3; Supplementary Table 23). The next best associations were seen with longitudinal executive functioning $\left(r^{2}=0.028 ; P=9.79 \mathrm{E}-03\right.$; Supplementary Table 23) and visuoconstructional abilities $\left(r^{2}=0.058 ; P=3.08 \mathrm{E}-03\right.$; Supplementary Table 23). However, these

383 latter two associations do not survive multiple testing correction (Table 3). Interestingly and similar to the MRI-based results, we did not find strong evidence for a genetic overlap between the neurocognitive outcomes tested here and AD risk based on Jansen et al. (2019) (Supplementary Table 23). This included the various phenotypes measuring components of "memory" performance, regardless of whether or not they were ascertained cross-sectionally or longitudinally.

\section{Discussion}

This study extends previous GWAS analyses from our group utilizing phenotypic data from the EMIF-AD MBD study (Hong et al., 2020; Hong et al., 2021). The overarching goal of this work was to decipher the genetic architecture of AD-related MRI and neuropsychological (endo)phenotypes to better understand AD pathophysiology. Both previous EMIF-AD MBD GWAS focused on AD biomarkers measured in CSF and, among other findings, identified variants in TMEM106B as transpQTLs of CSF neurofilament light (NfL) levels (Hong et al., 2021). Interestingly, the same locus was subsequently highlighted as a novel AD risk locus in a GWAS on $>1.1$ million individuals (Wightman et al. 2021), showcasing the power of the quantitative biomarker GWAS approach that was also followed in this study. In the current work, we focused on biomarkers / phenotypes derived from brain imaging and neuropsychological testing in the same EMIF-AD MBD individuals. Overall, we performed 19 individual GWAS and identified a total of 13 genome-wide significant loci highlighting several novel genes that are potentially involved in contributing to AD pathophysiology. Our study represents one of few GWAS in the literature to also include the X chromosome, where we identified a genome-wide significant association between markers near IL1RAPL1 and longitudinal visuoconstructive ability. Interestingly, neither $A P O E$ nor the other recently described AD GWAS loci appear to have a major impact on the traits analyzed in our study. In summary, our extensive genome-wide analyses nominate several novel loci potentially involved in neurocognitive functioning. Some of these may prove informative to better understand the genetic forces underlying $\mathrm{AD}$ and related phenotypes.

In the remainder of this section, we discuss the potential role of five loci, which we consider the most interesting findings of our study. The strongest GWAS signal was elicited by SNP rs73045836 $(P=7.50 \mathrm{E}-11$; Table 2; Figure 1B; Supplementary Figure 25) showing genome-wide significant association with the longitudinal data of the immediate recall memory phenotype. The gene annotated to the associated region on chromosome 6q27, SMOC2, encodes secreted modular calcium-binding protein 2. SMOC2 is an extracellular matrix protein from the secreted protein, acidic 
medRxiv preprint doi: https://doi.org/10.1101/2021.12.22.21268168; this version posted December 27, 2021. The copyright holder for this preprint (which was not certified by peer review) is the author/funder, who has granted medRxiv a license to display the preprint in perpetuity.

and rich in cysteine (SPARC) family (Gao et al., 2019) recently linked to age-dependent bone loss in humans (Morkmued et al., 2020). Despite performing careful literature and database searches, we could not pinpoint any obvious mechanistic connection of this locus to cognitive functioning or other AD-relevant phenotypes.

418 The second strongest association signal was observed near SNP rs5943462 (MAF 0.05) on the X chromosome ( $P=1.06 \mathrm{E}-09$; Table 2; Figure 1B; Supplementary Figure 29) with the longitudinal data of the visuoconstruction phenotype. The SNP is located in an intron of IL1RAPL1. This gene encodes interleukin 1 receptor accessory protein-like 1, which belongs to a class of molecules that regulate synapse formation. ILIRAPLI is mostly expressed in brain areas that are involved in memory development, such as hippocampus, dentate gyrus, and entorhinal cortex, suggesting that the protein may have a specialized role in physiological processes underlying memory and learning abilities (Montani et al., 2019). Even small changes in the expression and function of these proteins can provoke major alterations in synaptic connectivity, resulting in cognitive damage (Montani et al., 2019). Moreover, ILIRAPLI was nominated as a candidate gene for X-linked mental retardation (Raymond, 2006). Although the GWAS on longitudinal visuoconstruction included only 149 individuals, we believe this signal to be plausible and very interesting because of the well-established role of ILIRAPL1 on human brain function.

The third highlighted signal relates to the association between variant rs74381761 (MAF 0.05) on chromosome 8p23.1 ( $P=1.89 \mathrm{E}-08$; Table 2; Figure 1B; Supplementary Figure 5) and longitudinal MMSE measurements. This SNP is located in an intergenic region near TNKS. This gene encodes the protein tankyrase, which belongs to a class of poly (ADP-ribose) polymerases and is involved in various processes in the body, such as telomere regulation, Wnt/ $\beta$-catenin signaling pathway or glucose transport (Damale et al., 2020). According to GTEx (Lonsdale et al., 2013), TNKS is highly expressed in brain (mostly in cerebellum). Moreover, SNPs annotated to TNKS were associated with brain white matter hyperintensity (WMH) measurements (Armstrong et al., 2020; Sargurupremraj et al., 2020; Zhao et al., 2021) and cortical surface area measurements (Grasby et al., 2020) according to the GWAS catalog (Buniello et al., 2019). With a gene-based $P$ value of 4.87E-04 and the strong functional link to brain function, we consider the signal around $T N K S$ as plausible and very interesting.

The last highlighted finding from the longitudinal analyses relates to the genome-wide significant association observed between SNP rs9652864 and the delayed recall memory phenotype $(P=3.20 \mathrm{E}-$ 08; Table 2; Figure 1B; Supplementary Figure 21). This variant (MAF=0.218) attained a $P$ value of 6.73E-04 in the GWAS of Davies (2018) on cross-sectional cognitive performance, lending additional support to our finding. The SNPs is located in an intron of CEP112 which encodes centrosomal protein 112. Centrosomal proteins are known as the components of the centrosome involved in centriole biogenesis, cell cycle progression, and spindle-kinetochore assembly control

451

452

453 (Mazaheri Moghaddam et al., 2021). Despite showing only low levels of expression in the central nervous system (CNS) according to GTEx, SNPs in this gene have been associated with cortical surface area by neuroimaging in two independent GWAS (Grasby et al., 2020; van der Meer et al., 2020) according to the GWAS catalog (Buniello et al., 2019). However, none of these neuroimaging SNPs is in relevant LD $\left(r^{2}>0.6\right)$ to the lead variant identified here. Notwithstanding, given that variants in this gene have shown genetic links to both cognitive function and structural brain imaging, we consider this finding as plausible and highly interesting. 
medRxiv preprint doi: https://doi.org/10.1101/2021.12.22.21268168; this version posted December 27, 2021. The copyright holder for this preprint (which was not certified by peer review) is the author/funder, who has granted medRxiv a license to display the preprint in perpetuity.

460

461

462

463

464

465

466

467

468

469

470

471

472

473

474

475

476

477

478

479

480

481

482

483

484

485

486

487

488

489

490

491

492

493

494

495

496

497

498

499

500

501

502

503

504

505

506 interesting finding ( $P=1.17 \mathrm{E}-07$; Table 2; Figure 1A; Supplementary Figure 20). This protein interacts with Eps15-homology domain-containing protein 1/2 (EHD1/2) that plays a central role in GLUT4 transport and couples endocytic vesicles to the actin cytoskeleton (Rai et al., 2020). It is highly expressed in many tissues, including the brain, according to GTEx (Lonsdale et al., 2013). While there does not appear to be an obvious link between $E H B P 1$ and brain function in the literature (e.g. in the GWAS catalog [Buniello et al., 2019]), we note that this gene is located within $5 \mathrm{~kb}$ of OTX1 (orthodenticle homeobox 1; gene-based $P=1.19 \mathrm{E}-05$ ), which acts as transcription factor and plays a role in brain and sensory organ development in Drosophila and vertebrates, including humans (Omodei et al., 2009). Our lead SNP in this region, i.e. rs6705798, falls just short of attaining genome-wide significance ( $P=8.78 \mathrm{E}-08$; Table 2; Figure 1A) and is reported to represent an eQTL of both $O T X 1$ and EHBPI in various human tissues according to GTEx (Lonsdale et al., 2013).

In addition to searching for novel genetic determinants of the neuroimaging and neurocognitive traits analyzed in this study, we also investigated the overlap with known GWAS findings. First and foremost, this relates to two commonly studied alleles in the APOE gene, which appear to only play a minor role in this setting. Specifically, SNP rs429358, which defines the $\varepsilon 4$ allele in APOE, does not even reach genome-wide suggestive significance $(P<1.0 \mathrm{E}-05)$ in any of the 19 GWAS investigated here. The strongest associations with this allele were seen with MRI-based hippocampus volume (left volume $P=0.0002$, summed volume $P=0.0005$; Supplementary Table 20) and with the delayed recall memory test (baseline $P=0.0005$, longitudinal $P=0.0042$; Supplementary Table 20). The effect directions of these associations are consistent with the deleterious influence of rs429358 on AD (Neu et al., 2017). These at best marginal associations are in line with the literature: In the GWAS on cognitive function by Davies (2018), APOE $\varepsilon 4$ also only showed marginal association ( $P=2.2 \mathrm{E}-04)$, while it was not reported to show any evidence of association with hippocampal volume in the GWAS by Hibar (2017). These findings are different from our earlier GWAS in the EMIF-AD MBD dataset, where the $\varepsilon 4$ allele showed very pronounced evidence of association in CSF and imaging markers related to $\mathrm{A} \beta 42$ (Hong et al., 2020). Extending the comparison to additional genetic variants associated with AD risk in the GWAS by Jansen et al. (2019) did also not show any noteworthy or consistent overlap with the GWAS results generated in this study. In contrast, highly significant overlaps by PGS analy sis were observed upon using GWAS results from Davies et al. (2018) for the neuropsychological and Hibar et al. (2017) for the MRI phenotypes, which is not surprising given that very similar neuropsychological and neuroimaging traits were used as outcomes in these studies. Collectively, the PGS results of this and previous work show that there is only very limited overlap in the genetic architecture (at least when studying common SNPs) between AD on the one and neuropsychological performance or structural brain imaging on the other hand. We note that this does not preclude the possibility that certain molecular pathways targeted by the genes highlighted in this GWAS may be shared with AD pathophysiology.

While our study has several noteworthy strengths (e.g. the use of highly standardized procedures in generating and harmonizing both the genotype and phenotype data of our study, use of both crosssectional and longitudinal neurocognitive performance data, inclusion of the $\mathrm{X}$ chromosome in the GWAS), it may also have been negatively affected by some limitations. First and foremost, we note that the sample size used for the present analyses is comparatively small for "GWAS standards" and was well under 1,000 in some instances (Table 1). Accordingly, the statistical power of these analyses was low. This limitation is at least partially countered by the quantitative nature of nearly all analyzed phenotypes: it is well established that quantitative trait association analyses are more powerful than those using binary phenotypes, e.g. in a case-control setting (Bush and Moore, 2012). Second, in addition to resulting in low power, small sample sizes also increase the possibility of false-positive findings, especially for infrequent variants (i.e. those with an MAF $<5 \%$ ). In this 
507

508

509

510

511

512

513

514

515

516

517

518

519

520

521

522

523

524

525

526

527

528

529

530

531

532

533

534

535

536

537

538

539

540

541

542

543

544

545

546

547

548

549

550

context we note that eight of our thirteen genome-wide significant signals were elicited by such variants. Thus, independent replication - ideally in larger datasets - is needed to confirm the main findings of our GWAS before any further-reaching conclusions can be reached. Third, we note that the phenotype data used as outcome traits in our GWAS analyses were collected at different participating centers at times using different types of examinations (e.g. different tests to study the same overarching neuropsychological domain). To alleviate potential bias resulting from this inherent phenotypic heterogeneity, all clinical data were processed, quality-controlled and harmonized (e.g. by normalizing most variables within centers) centrally by an experienced team of researchers (see Bos et al. (2018) for more details). We emphasize that this potential heterogeneity does not apply to the genetic data as these were generated in one laboratory experiment and subsequently processed jointly in one analytical framework, minimizing the emergence of potential batch effects. Last but not least, we emphasize that owing to its particular ascertainment design (Bos et al., 2018) the EMIF-AD MBD dataset does not (attempt to) constitute a representative sample from the "general population". Accordingly, the results presented here cannot be generalized to the general population. We note that the same is true for many GWAS in this and other fields, which typically use clinic-based ascertainment which is not representative of the population as a whole.

In conclusion, our study delivers an entirely novel set of GWAS results from participants of the EMIF-AD MBD dataset. We nominate several novel and functionally interesting genetic association signals with phenotypes related to neurocognitive function and structural brain imaging. Even though independent replication is still needed, our results may prove informative to better understand the genetic forces underlying $\mathrm{AD}$ and related phenotypes.

\section{Conflict of Interest}

HZ has served at scientific advisory boards and/or as a consultant for Abbvie, Alector, Annexon, Artery Therapeutics, AZTherapies, CogRx, Denali, Eisai, Nervgen, Pinteon Therapeutics, Red Abbey Labs, Passage Bio, Roche, Samumed, Siemens Healthineers, Triplet Therapeutics, and Wave, has given lectures in symposia sponsored by Cellectricon, Fujirebio, Alzecure, Biogen, and Roche, and is a co-founder of Brain Biomarker Solutions in Gothenburg AB (BBS), which is a part of the GU Ventures Incubator Program. FB is supported by the NIHR biomedical research centre at UCLH. JP received consultation honoraria from Nestle Institute of Health Sciences, Ono Pharma, OM Pharma, and Fujirebio, unrelated to the submitted work. CET has a collaboration contract with ADx Neurosciences, Quanterix and Eli Lilly, performed contract research or received grants from ACImmune, Axon Neurosciences, Biogen, Brainstorm Therapeutics, Celgene, EIP Pharma, Eisai, PeopleBio, Roche, Toyama, Vivoryon. She serves on editorial boards of Medidact Neurologie/Springer, Alzheimer Research and Therapy, Neurology: Neuroimmunology \& Neuroinflammation, and is editor of a Neuromethods book Springer. CET also holds a speaker's contract with Roche, Inc. KB has served as a consultant, at advisory boards, or at data monitoring committees for Abcam, Axon, BioArctic, Biogen, JOMDD/Shimadzu. Julius Clinical, Lilly, MagQu, Novartis, Pharmatrophix, Prothena, Roche Diagnostics, and Siemens Healthineers, and is a cofounder of Brain Biomarker Solutions in Gothenburg AB (BBS), which is a part of the GU Ventures Incubator Program, outside the work presented in this paper. SL is an employee of Janssen-Cilag. JS is an employee and chief medical officer of AC Immune SA. The other authors declare that the research was conducted in the absence of any commercial or financial relationships that could be construed as a potential conflict of interest.

\section{Author Contributions}


medRxiv preprint doi: https://doi.org/10.1101/2021.12.22.21268168; this version posted December 27, 2021. The copyright holder for this preprint (which was not certified by peer review) is the author/funder, who has granted medRxiv a license to display the preprint in perpetuity.

551

552

553

554

555

556

557

558

559

560

561

562

563

564

565

566

567

568

569

570

571

572

573

574

575

576

577

578

579

580

581

582

583

584

585

586

587

588

589

590

591

592

593

594

595

$\mathrm{JH}$ and TO performed all the analyses and together with LB interpreted the data and wrote the manuscript. OO performed X chromosomal analyses. VD was responsible for EMIF-AD MBD DNA sample preparation and DNA extraction. LD contributed to the interpretation of the data and visualization of the results. IB, SV, and PJV coordinated the collection and harmonization of phenotypes and biosamples in EMIF-AD MBD. MW and AF supervised the genotyping experiments. RV, SG, JS, PS, CT, SE, GF, OB, JR, RB, AL, DA, JP, CC, GP, PML, MT, RD, CLQ, KS, CVB, $\mathrm{CL}, \mathrm{KB}, \mathrm{HZ}, \mathrm{MTK}$, and FB contributed to sample and phenotype data collection. JS, PJV and SL are the lead PIs for the EMIF-AD MBD study as a whole and were in charge of designing and managing the platform. LB designed and supervised the genomics portion of the EMIF-AD MBD project and co-wrote all drafts of the manuscript. All authors critically revised all manuscripts drafts, read and approved the final manuscript.

\section{Funding}

The present study was conducted as part of the EMIF-AD MBD project, which has received support from the Innovative Medicines Initiative Joint Undertaking under EMIF grant agreement No. 115372 , the resources of which are composed of financial contribution $\mathrm{f}$ rom the European Union's Seventh Framework Program (FP7/2007-2013) and EFPIA companies' in kind contribution. Parts of this study were made possible through support from the German Research Foundation (DFG grant FOR2488: Main support by subproject "INF-GDAC" BE2287/7-1 to LB) and the Cure Alzheimer's Fund (to LB). RV acknowledges support by the Stichting Alzheimer Onderzoek (\#13007, \#11020, \#2017-032) and the Flemish Government (VIND IWT 135043). KB is supported by the Swedish Research Council (\#2017-00915); the Alzheimer Drug Discovery Foundation (ADDF), USA (\#RDAPB-201809-2016615); the Swedish Alzheimer Foundation (\#AF-742881), Hjärnfonden, Sweden (\#FO2017-0243); the Swedish state under the agreement between the Swedish government and the County Councils; the ALF-agreement (\#ALFGBG-715986); European Union Joint Program for Neurodegenerative Disorders (JPND2019-466-236); and the Alzheimer's Association 2021 Zenith Award (ZEN-21-848495). HZ is a Wallenberg Scholar supported by grants from the Swedish Research Council (\#2018-02532), the European Research Council (\#681712), and Swedish State Support for Clinical Research (\#ALFGBG-720931). SJBV received funding from the Innovative Medicines Initiative 2 Joint Undertaking under ROADMAP grant agreement No. 116020 and from ZonMw during the conduct of this study. Research at VIB-UAntwerp was in part supported by the University of Antwerp Research Fund and SAO-FRA 2018 0016. The Lausanne study was funded by a grant from the Swiss National Research Foundation (SNF320030_141179) to JP. Research of CET is supported by the European Commission (Marie Curie International Training Network, grant agreement No 860197 (MIRIADE), and JPND), Health Holland, the Dutch Research Council (ZonMW), Alzheimer Drug Discovery Foundation, The Selfridges Group Foundation, Alzheimer Netherlands, Alzheimer Association. CET is recipient of ABOARD, which is a public-private partnership receiving funding from ZonMW (\#73305095007) and Health Holland, Topsector Life Sciences \& Health (PPP-allowance; \#LSHM20106). More than 30 partners participate in ABOARD. ABOARD also receives funding from Edwin Bouw Fonds and Gieskes-Strijbisfonds.

\section{Acknowledgments}

The authors acknowledge the assistance of Ellen De Roeck, Naomi De Roeck, and Hanne Struyfs (UAntwerp) with data collection. We thank Mrs. Tanja Wesse and Mrs. Sanaz Sedghpour Sabet at the Institute of Clinical Molecular Biology, Christian-Albrechts-University of Kiel, Kiel, Germany for technical assistance with the GSA genotyping. We thank Dr. Fabian Kilpert for his assistance with the QC and genotype imputations and Marcel Schilling for his assistance on visualizing the 
medRxiv preprint doi: https://doi.org/10.1101/2021.12.22.21268168; this version posted December 27, 2021. The copyright holder for this preprint (which was not certified by peer review) is the author/funder, who has granted medRxiv a license to display the preprint in perpetuity. All rights reserved. No reuse allowed without permission in EMIF-AD MBD dataset

596

597

598

599

600

601

602

603

604

605

606

607

608

609

610

611

612

613

614

615

616

617

618

619

620

621

622

623

624

625

626

627

628

629

630

631

632

633

634

635 results. The LIGA team acknowledges computational support from the OMICS compute cluster at the University of Lübeck.

\section{References}

Armstrong, N. J., Mather, K. A., Sargurupremraj, M., Knol, M. J., Malik, R., Satizabal, C. L., et al. (2020). Common Genetic Variation Indicates Separate Causes for Periventricular and Deep White Matter Hyperintensities. Stroke, 51:7, 2111-2121. doi:10.1161/STROKEAHA.1 19.027544

Bertram, L., and Tanzi, R. E. (2020). Genomic mechanisms in Alzheimer's disease. Brain pathology (Zurich, Switzerland), 30:5,966-977.doi:10.1111/bpa.12882

Bos, I., Vos, S., Vandenberghe, R., Scheltens, P., Engelborghs, S., Frisoni, G., et al. (2018). The EMIF-AD Multimodal Biomarker Discovery study: design, methods and cohort characteristics. Alzheimer's research and therapy, 10:1, 64. doi:10.1186/s13195-018-0396-5

Boyle, A. P., Hong, E. L., Hariharan, M., Cheng, Y., Schaub, M. A., Kasowski, M., et al. (2012). Annotation of functional variation in personal genomes using RegulomeDB. Genome research, 22:9, 1790-1797. doi:10.1101/gr.137323.112

Buniello, A., MacArthur, J., Cerezo, M., Harris, L. W., Hayhurst, J., Malangone, C., et al. (2019). The NHGRI-EBI GWAS Catalog of published genome-wide association studies, targeted arrays and summary statistics 2019. Nucleic acids research, 47:D1, D1005-D1012. doi:10.1093/nar/gky1120

Bush, W. S., and Moore, J. H. (2012). Chapter 11: Genome-wide association studies. PLoS computational biology, 8:12, e1002822. doi:10.1371/journal.pcbi.1002822

Cacace, R., Sleegers, K., and Van Broeckhoven, C. (2016). Molecular genetics of early -onset Alzheimer's disease revisited. Alzheimer's \& dementia: the journal of the Alzheimer's Association, 12:6, 733-748. doi:10.1016/j.jalz.2016.01.012

Choi, S. W., and O'Reilly, P. F. (2019). PRSice-2: Polygenic Risk Score software for biobank-scale data. GigaScience, 8(7), giz082. doi:10.1093/gigascience/giz082

Damale, M. G., Pathan, S. K., Shinde, D. B., Patil, R. H., Arote, R. B., and Sangshetti, J. N. (2020). Insights of tankyrases: A novel target for drug discovery. European journal of medicinal chemistry, 207, 112712. doi:10.1016/j.ejmech.2020.112712

Das, S., Forer, L., Schönherr, S., Sidore, C., Locke, A. E., Kwong, A., et al. (2016). Next-generation genotype imputation service and methods. Nature genetics, 48:10, 1284-1287. doi:10.1038/ng.3656

Davies, G., Lam, M., Harris, S. E., Trampush, J. W., Luciano, M., Hill, W. D., et al. (2018). Study of 300,486 individuals identifies 148 independent genetic loci influencing general cognitive function. Nature communications, 9:1, 2098. doi:10.1038/s41467-018-04362-X

de Leeuw, C. A., Mooij, J. M., Heskes, T., and Posthuma, D. (2015). MAGMA: generalized gene-set analysis of GWAS data. PLoS computational biology, 11:4, e1004219.

doi:10.1371/journal.pcbi.1004219 
medRxiv preprint doi: https://doi.org/10.1101/2021.12.22.21268168; this version posted December 27, 2021. The copyright holder for this preprint (which was not certified by peer review) is the author/funder, who has granted medRxiv a license to display the preprint in perpetuity. All rights reserved. No reuse allowed without permission in EMIF-AD MBD dataset

636

637

638

639

640

641

642

643

644

645

646

647

648

649

650

651

652

653

654

655

656

657

658

659

660

661

662

663

664

665

666

667

668

669

670

671

672

673

674

675

676

677

678

Gao, Q., Mok, H. P., and Zhuang, J. (2019). Secreted modular calcium-binding proteins in pathophysiological processes and embryonic development. Chinese medical journal, 132:20, 24762484. doi:10.1097/CM9.0000000000000472

Gatz, M., Reynolds, C. A., Fratiglioni, L., Johansson, B., Mortimer, J. A., Berg, S., et al. (2006). Role of genes and environments for explaining Alzheimer disease. Archives of general psychiatry, 63:2,168-174. doi:10.1001/archpsyc.63.2.168

Gottesman, I. I., and Gould, T. D. (2003). The endophenotype concept in psychiatry: etymology and strategic intentions. The American journal of psychiatry, 160:4, 636-645.

doi:10.1176/appi.ajp.160.4.636

Graffelman, J., and Weir, B. S. (2016). Testing for Hardy-Weinberg equilibrium at biallelic genetic markers on the X chromosome. Heredity, 116:6, 558-568. doi:10.1038/hdy.2016.20

Grasby, K. L., Jahanshad, N., Painter, J. N., Colodro-Conde, L., Bralten, J., Hibar, D. P., et al. (2020). The genetic architecture of the human cerebral cortex. Science (New York, N.Y.), 367:6484, eaay6690. doi:10.1126/science.aay6690

Hibar, D. P., Adams, H., Jahanshad, N., Chauhan, G., Stein, J. L., Hofer, M. A., et al. (2017). Novel genetic loci associated with hippocampal volume. Nature communications, 8, 13624.

doi:10.1038/ncomms 13624

Holtzman, D. M., Herz, J., and Bu, G. (2012). Apolipoprotein E and apolipoprotein E receptors: normal biology and roles in Alzheimer disease. Cold Spring Harbor perspectives in medicine, 2:3, a006312. doi:10.1101/cshperspect.a006312

Hong, S., Prokopenko, D., Dobricic, V., Kilpert, F., Bos, I., Vos, S., et al. (2020). Genome-wide association study of Alzheimer's disease CSF biomarkers in the EMIF-AD Multimodal Biomarker Discovery dataset. Translational psychiatry, 10:1,403. doi:10.1038/s41398-020-01074-z

Hong, S., Dobricic, V., Ohlei, O., Bos, I., Vos, S., Prokopenko, D., et al. (2021). TMEM106B and $\mathrm{CPOX}$ are genetic determinants of cerebrospinal fluid Alzheimer's disease biomarker levels. Alzheimer's and dementia : the journal of the Alzheimer's Association, 17:10, 1628-1640. doi:10.1002/alz.12330

Jansen, I. E., Savage, J. E., Watanabe, K., Bryois, J., Williams, D. M., Steinberg, S., et al. (2019). Genome-wide meta-analysis identifies new loci and functional pathways influencing Alzheimer's disease risk. Nature genetics, 51:3, 404-413. doi:10.1038/s41588-018-0311-9

Lonsdale, J., Thomas, J., Salvatore, M., Phillips, R., Lo, E., Shad, S., et al. (2013). The GenotypeTissue Expression (GTEx) project. Nature genetics, 45:6, 580-585. doi:10.1038/ng.2653

Machiela, M. J., and Chanock, S. J. (2015). LDlink: a web-based application for exploring population-specific haplotype structure and linking correlated alleles of possible functional variants. Bioinformatics (Oxford, England), 31:21, 3555-3557. doi:10.1093/bioinformatics/btv402

MacRae, C. A., and Vasan, R. S. (2011). Next-generation genome-wide association studies: time to focus on phenotype?. Circulation. Cardiovascular genetics, 4:4, 334-336.

doi:10.1161/CIRCGENETICS.111.960765 
medRxiv preprint doi: https://doi.org/10.1101/2021.12.22.21268168; this version posted December 27, 2021. The copyright holder for this preprint (which was not certified by peer review) is the author/funder, who has granted medRxiv a license to display the preprint in perpetuity. All rights reserved. No reuse allowed without permission in EMIF-AD MBD dataset

679

680

681

682

683

684

685

686

687

688

689

690

691

692

693

694

695

696

697

698

699

700

701

702

703

704

705

706

707

708

709

710

711

712

713

714

715

716

717

718

719

720

721

722

723

Martin, P. M., Carnaud, M., Garcia del Caño, G., Irondelle, M., Irinopoulou, T., Girault, J. A., et al. (2008). Schwannomin-interacting protein-1 isoform IQCJ-SCHIP-1 is a late component of nodes of Ranvier and axon initial segments. The Journal of neuroscience : the official journal of the Society for Neuroscience, 28:24, 6111-6117. doi:10.1523/JNEUROSCI.1044-08.2008

Mattsson, N., Carrillo, M. C., Dean, R. A., Devous, M. D., Sr, Nikolcheva, T., Pesini, P., et al. (2015). Revolutionizing Alzheimer's disease and clinical trials through biomarkers. Alzheimer's \& dementia (Amsterdam, Netherlands), 1:4,412-419.doi:10.1016/j.dadm.2015.09.001

Martin, P. M., Cifuentes-Diaz, C., Devaux, J., Garcia, M., Bureau, J., Thomasseau, S., et al. (2017). Schwannomin-interacting Protein 1 Isoform IQCJ-SCHIP1 Is a Multipartner Ankyrin- and Spectrinbinding Protein Involved in the Organization of Nodes of Ranvier. The Journal of biological chemistry, 292:6, 2441-2456. doi:10.1074/jbc.M1 16.758029

Mazaheri Moghaddam, M., Mazaheri Moghaddam, M., Hamzeiy, H., Baghbanzadeh, A., Pashazadeh, F., and Sakhinia, E. (2021). Genetic basis of acephalic spermatozoa syndrome, and intracy toplasmic sperm injection outcomes in infertile men: a systematic scoping review. Journal of assisted reproduction and genetics, 38:3, 573-586. doi:10.1007/s10815-020-02008-w

McCarthy, S., Das, S., Kretzschmar, W., Delaneau, O., Wood, A. R., Teumer, A., et al. (2016). A reference panel of 64,976 haplotypes for genotype imputation. Nature genetics, 48:10, 1279-1283. doi:10.1038/ng.3643

McLaren, W., Gil, L., Hunt, S. E., Riat, H. S., Ritchie, G. R., Thormann, A., et al. (2016). The Ensembl Variant Effect Predictor. Genome biology, 17:1, 122. doi:10.1186/s13059-016-0974-4

Montani, C., Gritti, L., Beretta, S., Verpelli, C., and Sala, C. (2019). The Synaptic and Neuronal Functions of the X-Linked Intellectual Disability Protein Interleukin-1 Receptor Accessory Protein Like 1 (IL1RAPL1). Developmental neurobiology, 79:1, 85-95. doi:10.1002/dneu.22657

Morkmued, S., Clauss, F., Schuhbaur, B., Fraulob, V., Mathieu, E., Hemmerlé, J., et al. (2020). Deficiency of the SMOC2 matricellular protein impairs bone healing and produces age-dependent bone loss. Scientific reports, 10:1, 14817. doi:10.1038/s41598-020-71749-6

Neu, S. C., Pa, J., Kukull, W., Beekly, D., Kuzma, A., Gangadharan, P., et al. (2017). Apolipoprotein E Genotype and Sex Risk Factors for Alzheimer Disease: A Meta-analy sis. JAMA neurology, 74:10, 1178-1189. doi:10.1001/jamaneurol.2017.2188

Omodei, D., Acampora, D., Russo, F., De Filippi, R., Severino, V., Di Francia, R., et al. (2009). Expression of the brain transcription factor OTX1 occurs in a subset of normal germinal-center B cells and in aggressive Non-Hodgkin Lymphoma. The American journal of pathology, 175:6, 26092617. doi:10.2353/ajpath.2009.090542

Patterson, C. (2018) World Alzheimer Report 2018. The State of the Art of Dementia Research: New Frontiers. An Analysis of Prevalence, Incidence, Cost and Trends. Alzheimer's Disease International.

Purcell, S., Neale, B., Todd-Brown, K., Thomas, L., Ferreira, M. A., Bender, D., et al. (2007). PLINK: a tool set for whole-genome association and population-based linkage analyses. American journal of human genetics, 81:3, 559-575. doi:10.1086/519795 
medRxiv preprint doi: https://doi.org/10.1101/2021.12.22.21268168; this version posted December 27, 2021. The copyright holder for this preprint (which was not certified by peer review) is the author/funder, who has granted medRxiv a license to display the preprint in perpetuity. All rights reserved. No reuse allowed without permission in EMIF-AD MBD dataset

724

725

726

727

728

729

730

731

732

733

734

735

736

737

738

739

740

741

742

743

744

745

746

747

748

749

750

751

752

753

754

755

756

757

758

759

760

761

762

763

764

765

Quintino-Santos, S., Diniz, B. S., Firmo, J. O., Moriguchi, E. H., Lima-Costa, M. F., and CastroCosta, E. (2015). APOE $\varepsilon 4$ allele is associated with worse performance in memory dimensions of the mini-mental state examination: the Bambuí Cohort Study of Aging. International journal of geriatric psychiatry, 30:6, 573-579. doi:10.1002/gps.4186

Rai, A., Bleimling, N., Vetter, I. R., and Goody, R. S. (2020). The mechanism of activation of the actin binding protein EHBP1 by Rab8 family members. Nature communications, 11:1, 4187. doi:10.1038/s41467-020-17792-3

Raymond F. L. (2006). X linked mental retardation: a clinical guide. Journal of medical genetics, 43:3, 193-200. doi:10.1136/jmg.2005.033043

Rentzsch, P., Schubach, M., Shendure, J., and Kircher, M. (2021). CADD-Splice-improving genomewide variant effect prediction using deep learning-derived splice scores. Genome medicine, 13:1,31. doi:10.1186/s13073-021-00835-9

Sargurupremraj, M., Suzuki, H., Jian, X., Sarnowski, C., Evans, T. E., Bis, J. C., et al. (2020).

Cerebral small vessel disease genomics and its implications across the lifespan. Nature communications, 11:1, 6285. doi:10.1038/s41467-020-19111-2

Scheufele, E., Aronzon, D., Coopersmith, R., McDuffie, M. T., Kapoor, M., Uhrich, C. A., et al. (2014). tranSMART: An Open Source Knowledge Management and High Content Data Analytics Platform. AMIA Joint Summits on Translational Science proceedings. AMIA Joint Summits on Translational Science, 2014, 96-101.

Smith, S. M., Douaud, G., Chen, W., Hanayik, T., Alfaro-Almagro, F., Sharp, K., et al. (2021). An expanded set of genome-wide association studies of brain imaging phenotypes in UK Biobank. Nature neuroscience, 24:5, 737-745. doi:10.1038/s41593-021-00826-4

Sperling, R., Mormino, E., and Johnson, K. (2014). The evolution of preclinical Alzheimer's disease: implications for prevention trials. Neuron, 84:3, 608-622. doi: 10.1016/j.neuron.2014.10.038

Ten Kate, M., Redolfi, A., Peira, E., Bos, I., Vos, S. J., Vandenberghe, R., et al. (2018). MRI predictors of amyloid pathology: results from the EMIF-AD Multimodal Biomarker Discovery study. Alzheimer's research \& therapy, 10:1, 100. doi:10.1186/s13195-018-0428-1

van der Meer, D., Frei, O., Kaufmann, T., Shadrin, A. A., Devor, A., Smeland, O. B., et al. (2020). Understanding the genetic determinants of the brain with MOSTest. Nature communications, 11:1, 3512. doi:10.1038/s41467-020-17368-1

Watanabe, K., Taskesen, E., van Bochoven, A., and Posthuma, D. (2017). Functional mapping and annotation of genetic associations with FUMA. Nature communications, 8:1, 1826.

doi:10.1038/s41467-017-01261-5

Wightman, D. P., Jansen, I. E., Savage, J. E., Shadrin, A. A., Bahrami, S., Holland, D., et al. (2021). A genome-wide association study with 1,126,563 individuals identifies new risk loci for Alzheimer's disease. Nature genetics, 53:9, 1276-1282. doi:10.1038/s41588-021-00921-z 
medRxiv preprint doi: https://doi.org/10.1101/2021.12.22.21268168; this version posted December 27, 2021. The copyright holder for this preprint (which was not certified by peer review) is the author/funder, who has granted medRxiv a license to display the preprint in perpetuity. All rights reserved. No reuse allowed without permission in EMIF-AD MBD dataset

766

767

768

769

770

771

772

773

774

775

776

777

778

779

780

781

782

783

784

785

786

787

788

789

Willer, C. J., Li, Y., and Abecasis, G. R. (2010). METAL: fast and efficient meta-analysis of genomewide association scans. Bioinformatics (Oxford, England), 26:17, 2190-2191.

doi:10.1093/bioinformatics/btq340

Zhang, Q., Cai, Z., Lhomme, M., Sahana, G., Lesnik, P., Guerin, M., et al. (2020). Inclusion of endophenotypes in a standard GWAS facilitate a detailed mechanistic understanding of genetic elements that control blood lipid levels. Scientific reports, 10:1, 18434. doi:10.1038/s41598-020$75612-6$

Zhao, B., Zhang, J., Ibrahim, J. G., Luo, T., Santelli, R. C., Li, Y., et al. (2021). Large-scale GWAS reveals genetic architecture of brain white matter microstructure and genetic overlap with cognitive and mental health traits $(\mathrm{n}=17,706)$. Molecular psychiatry, 26:8, 3943-3955. doi:10.1038/s41380$019-0569-\mathrm{z}$

\section{Data Availability Statement}

GWAS summary statistics for the top $(P$ value $<1.0 \mathrm{E}-05)$ results are listed in the Supplementary Tables. Full GWAS summary statistics are available from the authors upon request. Clinical data and genome-wide genotyping data are stored on an online data platform using the "tranSMART" data warehouse framework. Access to the genome-wide genotyping data can be requested from the corresponding author of this study who will forward each request to the EMIF-AD data access team.

All scripts used to generate the primary GWAS and PGS analyses are available from the authors upon request.

\section{Figure legends}

Figure 1: Multi-trait Manhattan plots for the SNP-based GWAS results on neuropsychological phenotypes (A: cross-sectional; B: longitudinal). For details on the analyzed traits see Methods and Supplementary Material. 
791 Table 1: Description of EMID-AD MBD datasets analyzed per phenotype.

"MAF filter" denotes the applied MAF filter for each GWAS. For cross-sectional MMSE we used an MAF threshold of 0.02 due to residual inflation of the GWAS test statistics. Information on tests used for generating baseline and longitudinal phenotypes can be found in the

794 Supplementary Material. MMSE = Mini Mental State Examination. "n.a." = not available.

\begin{tabular}{|l|l|l|l|l|l|}
\hline \multirow{5}{*}{ Category } & \multirow{2}{*}{ Phenotype } & \multicolumn{2}{|c|}{ Baseline } & \multicolumn{2}{|c|}{ Longitudinal } \\
\cline { 3 - 6 } & MMSE & Sample size & MAF filter & Sample size & MAF filter \\
\hline \multirow{5}{*}{ Neuropsychological } & Attention & 867 & 0.02 & 520 & 0.02 \\
& Executive functioning & 806 & 0.01 & 402 & 0.02 \\
& Language & 686 & 0.01 & 234 & 0.02 \\
& Memory Delayed & 849 & 0.01 & 409 & 0.02 \\
& Memory Immediate & 729 & 0.01 & 337 & 0.02 \\
& Visuoconstruction & 797 & 0.01 & 345 & 0.02 \\
MRI & Fazekas score & 629 & 0.02 & 149 & 0.04 \\
\hline & Cortical thickness & 566 & 0.01 & n.a. & n.a. \\
& Left Hippocampus volume & 605 & 0.01 & n.a. & n.a. \\
& Right Hippocampus volume & 605 & 0.01 & n.a. & n.a. \\
& Summed Hippocampus volume & 605 & 0.01 & n.a. & n.a. \\
\hline
\end{tabular}


796 Table 2: Genome-wide significant associations observed in GWAS of cognitive phenotypes.

797 Bold font indicates genome-wide significant (on SNP- or gene-level) results (see Methods section for details). "Chr" and "Position" according to GRCh37/hg19. "A1" denotes the effect allele. "P(SNP)" is the $P$ value of the lead SNP at this locus. "P(Gene)" is the $P$ value

799 belonging to "Nearest gene". Top results from these GWAS analyses can be found in the Supplementary Tables. MMSE = Mini Mental State 800 Examination. "n.a." = not available.

\begin{tabular}{|c|c|c|c|c|c|c|c|c|c|c|c|}
\hline Study arm & Phenotype & Lead variant & Chr & Position & Nearest gene & A1 & A2 & Beta & MAF & P (SNP) & P (Gene) \\
\hline \multirow{3}{*}{ Cross-sectional } & MemoryDelayed & rs6705798 & $2 \mathrm{p} 15$ & 63259881 & EHBP1 & $\mathrm{C}$ & $\mathrm{T}$ & -0.32739 & 0.358 & $8.78 \mathrm{E}-08$ & 1.17E-07 \\
\hline & MMSE & rs2122118 & $2 q 33.3$ & 207252439 & AC017081.2 & G & A & -2.82266 & 0.022 & 3.03E-09 & n.a. \\
\hline & Visuoconstruction & rs113492235 & $4 q 34.2$ & 177252900 & SPCS3 & $\mathrm{T}$ & C & -2.17956 & 0.022 & 1.51E-08 & 0.15674 \\
\hline \multirow{10}{*}{ Longitudinal } & MemoryImmediate & rs73045836 & $6 q 27$ & 169062739 & SMOC2 & G & $\mathrm{T}$ & -0.36094 & 0.020 & $7.50 \mathrm{E}-11$ & 0.0035373 \\
\hline & MMSE & rs74381761 & $8 p 23.1$ & 9389761 & $T N K S$ & $\mathrm{C}$ & G & -0.08453 & 0.048 & 1.89E-08 & 0.00048716 \\
\hline & Attention & rs116900143 & $10 \mathrm{q} 23.31$ & 92588290 & HTR7 & $\mathrm{C}$ & $\mathrm{T}$ & -0.35173 & 0.023 & $1.95 \mathrm{E}-08$ & 0.019663 \\
\hline & Memory Immediate & rs11217863 & $11 \mathrm{q} 23.3$ & 120293138 & AP002348.1 & A & G & -0.16626 & 0.080 & 7.81E-08 & 8.91E-07 \\
\hline & Attention & rs111959303 & $12 q 14.3$ & 66844015 & GRIP1 & $\mathrm{T}$ & $\mathrm{C}$ & 0.37459 & 0.022 & 2.52E-08 & 0.81478 \\
\hline & Attention & rs34736485 & $16 \mathrm{q} 23.2$ & 79272611 & RP11-679B19.2 & $\mathrm{T}$ & G & 0.31924 & 0.022 & 1.59E-08 & n.a. \\
\hline & MemoryDelayed & rs9652864 & $17 q 24.1$ & 63741645 & CEP112 & A & $\mathrm{T}$ & 0.29184 & 0.218 & 3.20E-08 & 0.016339 \\
\hline & Memory Immediate & rs146202660 & $18 \mathrm{q} 21.1$ & 45022937 & $C T D-2130013.1$ & $\mathrm{~T}$ & G & -0.29342 & 0.029 & 4.63E-08 & n.a. \\
\hline & Executive & rs16982556 & $20 q 13.32$ & 57801889 & ZNF831 & $\mathrm{T}$ & C & -0.29752 & 0.062 & $1.26 \mathrm{E}-08$ & 0.0025565 \\
\hline & Visuoconstruction & rs5943462 & $\mathrm{Xp} 21.3$ & 28823154 & ILIRAPLI & G & $\mathrm{C}$ & -0.14082 & 0.051 & 1.06E-09 & 0.006719 \\
\hline
\end{tabular}


Table 3: Summary of PGS results significant after multiple testing correction.

803 804 805 806 807

"Threshold" refers to $P$ value cut-off used for PGS construction in prior GWAS summary statistics and "Number of SNPs" refers to the LDpruned SNPs passing this threshold that are included in PGS calculations. "R2" denotes the phenotypic variance explained by the SNPs of the prior GWAS in the EMIF-AD MBD dataset. A full listing of results from these PRS analyses can be found in Supplementary Material. MMSE $=$ Mini Mental State Examination.

\begin{tabular}{|l|l|l|l|l|l|}
\hline Prior GWAS & Phenotype & Threshold & Number of SNPs & R2 & P value \\
\hline \multirow{4}{*}{ Hibar et al. (2017) } & Hippocampus volume sum & 0.0001 & 127 & 0.027 & $6.06 \mathrm{E}-06$ \\
& Hippocampus volume left & 0.0001 & 127 & 0.026 & $9.98 \mathrm{E}-06$ \\
& Hippocampus volume right & 0.0001 & 127 & 0.024 & $2.48 \mathrm{E}-05$ \\
\hline Jansen et al. (2019) & Fazekas & 0.17075 & 22269 & 0.014 & $3.72 \mathrm{E}-03$ \\
\hline & Baseline MMSE & 0.248 & 63792 & 0.016 & $1.66 \mathrm{E}-06$ \\
& Baseline executive functioning & 0.0014 & 4469 & 0.018 & $1.98 \mathrm{E}-05$ \\
& Baseline language & 0.0061 & 9031 & 0.010 & $1.25 \mathrm{E}-03$ \\
& Longitudinal attention & $5.0 \mathrm{E}-08$ & 163 & 0.023 & $1.79 \mathrm{E}-03$ \\
\hline
\end{tabular}




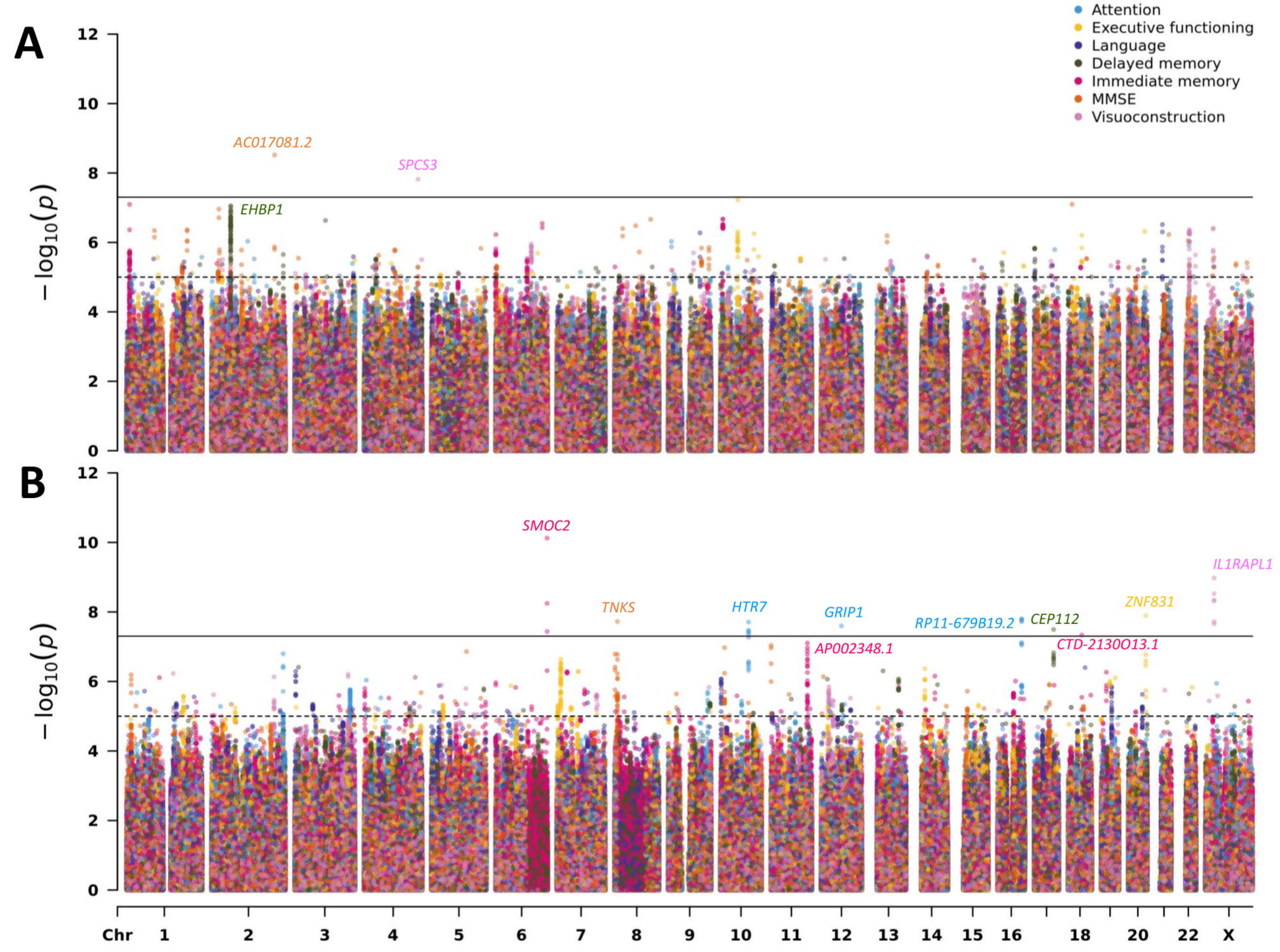

